\title{
EPIDEMIA DE HEPATITE VEICULADA POR GAMAGLOBULINA CONTAMINADA ${ }^{1}$
}

\author{
Anastácio Ferreira Morgado ${ }^{2}$, Joir Gonçalves da \\ Fonte ${ }^{3}$, Maria Guiomar Pereira da Silva ${ }^{4}$, José Rodrigues Coura 5 \\ Hermann Gonçalves Schatzmayr ${ }^{6}$ e Léa Camillo Coura ${ }^{7}$
}

Os autores estudaram uma epidemia de Hepatite $B$ em uma instituição localizada no bairro de São Cristovão na cidade do Rio de Janeiro, Brasil. Ocorreu um total de 35 casos: 30 entre os funcionários da instituição e cinco entre familiares de funcionários. Todos os casos foram considerados de hepatite aguda benígna; apenas dois não tiveram ictericia. Clinicamente, chamou-lhes a atenção um importante envolvimento articular: artralgias intensas, com grande restrição dos movimentos, durante o período de incubação e que regrediram completamente logo que a icterícia tornou-se evidente. A distribuição cronológica foi tipica de infecção simultânea em fonte única. A investigação epidemiológica revelou que essa fonte foi um produto terapêtutico derivado do sangue humano: gamaglobulina. As injeções foram feitas com seringas descartáveis e, irônicamente, com o objetivo de prevenir hepatite. Em dois dias de aplicação, cerca de 120 funcionários receberam a injeção de gamaglobulina, entre os quais 27 desenvolveram hepatite. O periodo de incubação médio foi de 116 dias. O Ag HB, testado em 26 pacientes, foi positivo em 12 (46.2\%); oito pacientes com tempo de doença inferior a duas semanas, foram todos positivos. O surto epidêmico ocorreu em condições que caracterizaram um estudo experimental, não planejado, em seres humanos.

Os autores estudaram, além do surto epidêmico de São Cristovão, oito casos vinculados ao serviço hospitalar onde trabalhavam. Esses casos apresentaram caracteristicas que os distinguiram dos casos de hepatite comumente ali tratados. Todos os pacientes eram de elevada classe social, com o antecedente de terem tomado injeção de gamaglobulina, da mesma procedência daquela que originou o surto epidêmico de São Cristovão. Nesses casos o período de incubação médio foi de 106 dias. Seis dos oito pacientes foram testados para o Ag HB, que foi positivo em cinco.

Onze partidas da gamaglobulina foram testadas, em laboratórios de referência da Organização Mundial de Saúde, encontrando-se o Ag HB em seis $(54,5 \%)$.

Os autores concluem que houve alguma falha grave no processo de preparo da gamaglobulina em apreço. E por isto deve-se ter reservas quanto à noção difundida de que esse medicamento está isento do risco de transmitir o virus hepatite.

\section{INTRODUÇÃO}

Em maio de 1974 os empregados e alguns de seus familiares, de uma empresa localizada no bairro de São Cristovão, Rio de Janeiro, foram atingidos por um surto epidêmico de hepatite. Os casos surgiram emı curto período de tempo e, em relação à população exposta ao risco, o seu número foi muito alto, gerando um problema que exigia solução imediata. Articulou-se uma equipe para esse fim, a qual logrou, em poucos dias, identificar a fonte de infecção e, com isto, pôde recomendar a adequada medida de controle.

Além do surto epidêmico os autores incluem neste estudo oito casos de hepatite ocorridos em pessoas que não tiveram qualquer vínculo com a referida empresa. Essa inclusão se justificou porque esses casos tiveram a mesma fonte de infecção verificada no surto epidêmico. A idenficação do mecanismo de transmissão de cada um dos oito casos só foi possível elucidar após a descoberta da fonte de infecção ao se investigar o surto epidêmico.

$\mathrm{Na}$ investigação do surto epidêmico descobriuse que a fonte de infecção foi gamaglobulina humana, vendida no mercado consumidor como produto terapẽutico. As circunstâncias que o geraram foram muito especiais, constituin-

1. Trabalho já apresentado sob forma de tese por Morgado (13)

2. Prof. Assistente de Epidemiologia da Escola Nacional de Saúde Publica - Fundação Oswaldo Cruz. Caixa Postal n. 8016.

3. Prof. Titular de Epidemiologia, Chefe do Dept ${ }^{\circ}$ de Epidemiologia e Métodos Quantitativos em Saúde da Escola Nacional de Saúde Pública - Fundação Oswaldo Cruz.

4. Epidemiologista da Secretaria de Saúde do Municipio do Rio de Janeiro.

5. Prof. Titular de Doenças Infecciosas e Parasitárias da Faculdade de Medicina da U.F.R.J. Chefe do Depto de Medicina Preventiva da U.F.R.J.

6. Pesquisador Titular e Chefe do Laboratório de Virus do Instituto Oswaldo Cruz. Fundação Oswaldo Cruz.

7. Professor Adjunto do Departamento de Medicina Preventiva da UFRJ. Orientadora da tese. 
do-se numa experiência não planejada em seres humanos, que mostrou constituir a gamaglobu. lina humana um risco de produzir hepatite. Até então, as raras investigações que admitiram a posbilidade de a gamaglobulina transmirir o vírus da hepatite não chegaram a convencer, por inexistência de elementos com valor de prova. O pressente trabalho coloca sob reserva o consenso geral de que o uso da gamaglobulina fosse intei. ramente inócuo. É um derivado do sangue humano e, como este, deve merecer rigoroso controle.

\section{MATERIAL E MÉTODOS}

Inicialmente foi feita uma investigação epidemiológica, minuciosa, do surto epidêmico de São Cristovão. Os pacientes foram encaminhados para a Clínica de Doenças Infecciosas e Parasitárias da Faculdade de Medicina da U.F.R.J., onde eram clinicamente examinados e colhidas amostras de sangue para exames laboratoriais. As dependências do edifício onde os doentes trabalhavam foram inspecionadas por especialistas em saneamento e várias amostras de água colhidas para exames de laboratórios. Um estoque de várias partidas da gamaglobulina incriminada na investigação foi apreendido para exames laboratoriais. A Comissão Nacional de Hemoterapia do Ministério da Saúde enviou alguns lotes desse estoque a laboratórios de referência da Organização Mundial da Saúde, a fim de complementar os exames aqui já realizados.

Com vistas a um maior rigor na identificação da fonte de infecção, planejou-se um estudo tipo caso-controle para testar as possiveis fontes encontradas na investigação epidemiológica. Elaborou-se um questionário concernente a exposição a esses prováveis fatores de risco, que foi respondido pelo grupo de casos e grupo controle. Inicialmente decidiu-se tomar como grupo controle os demais funcionários da empresa. Entretanto, surgiu uma dificuldade insuperável entre a diretoria da instituição sede do surto épidêmico e os investigadores, a qual impediu o prosseguimento do estudo e o desenvolvimento do método planejado. Uma alternativa foi tentada: conseguiu-se um controle para cada caso e mesmo assim com prejuizos no pareamento por idade. Em que pesem as reais limitações do grupo controle, ele contribuiu para reforçar a associação entre o surto epidêmico e a inoculação da gamaglobulina.

\section{RESULTADOS DO SURTO EPIDÊMICO}

\section{Quadro Clínico}

O surto epidêmico consistiu de um total de 35 casos, dos quais apenas dois $(5,7 \%)$ foram anictéricos. Estes apresentaram indisposição geral e anorexia em pleno período epidêmico. vindo o diagnóstico de hepatite a ser confirmado mediante exames de laboratório.

Não houve nenhum caso grave. Se is pacientes foram tratados em regime hospitalar porque não possuiam condições em suas residenncias para Ihes propiciar alimentação e repouso adequados. A icterícia da maioria dos pacientes foi relativamente fugaz: uma a duas semanas de duração; em alguns ela permaneceu por quatro a seis semanas. Nenhum se queixou de febre, diarréia ou constipação intestinal. O quadro clínico constituiu-se de indisposição geral e anorexia por um período de aproximadamente uma semana e a seguir surgia urina escura e as escleróticas se tornayam ictéricas.

Chamou a atenção, contudo, a elevada incidência de comprometimento articular, observada em onze pacientes $(31,4 \%)$ e caracterizado por artralgia de pequenas, médias e até de grandes articulações. Não havia edema nem qualquer deformidade nas articulações atingidas. As artralgias se intensificavam com os movimentos, às vezes limitando seriamente seus portadores. Caracteristicamente, esse envolvimento articular ocorreu no período prodrômico; Logo que surgia a icterícia as artralgias progressivamente diminuiam de intensidade, até desaparecerem por completo; não restou seqüela articular.

$O$ conhecimento da manisfestação articular na hepatite $B$ não é recente. Já em 1843 Graves $^{7}$ ensinava que na hepatite podia ocorrer uma síndrome similar à doença do soro. Todavia, o documento mais notável encontra-se na epidemia de hepatite B descrita por Mirick e Shank 12 . Entre os 302 casos de hepatite por eles estudados, observaram a ocorrência de artralgia, urticária, "rush" e edema angioneurótico em $28,5 \%, 20,0 \%, 13,9 \%$ e $4,3 \%$ dos casos, respecti. vamente. Hawley e Cols ao estudarem uma epidemia de hepatite $B$ ocorrida entre recrutas inoculados com plasma imune contra sarampo, encontraram a elevada proporção de $42,5 \%$ de fenômenos de hipersensibilidade. Fox e Cols ${ }^{6}$, descreveram uma epidemia de hepatite determinada por duas partidas distintas de vacina antiamarílica, ocorrendo artralgia em 23,0 e $33,0 \%$ dos pacientes inoculados com vacina de uma outra partida, respectivamente. Portanto, é bastante provável que não se identifique os fenômenos de hipersensibilidade nos casos esporádicos de hepatite $B$, porque são vistos quando já estão francamente ictéricos, com aqueles fenômenos já regredidos. 


\section{EVOLUÇÃO CRONOLÓGICA DO SURTO EPI- DÊMICO}

Considerou-se o aparecimento da colúría como o evento clínico para marcar o início da doença. Os dois casos anictéricos, nos quais a mudança na cor da urina foi quase imperceptível, o início da doença foi fixado pela data da coleta do sangue, cujo exame confirmou o diagnóstico.

Os 35 casos estão apresentados, segundo a respectiva semana de início, na Fig. 1. Essa distribuição cronológica possui uma característica marcante: uma pequena aglomeração de casos em dezembro de 1973 e uma outra, grande, centrada em abril de 1974. Esta segunda aglomeração é a espinha dorsal do surto epidêmico, pois ocorreram em bloco $27(77.1 \%)$ casos. Este conjunto de casos é altamente sugestivo de infecção simultânea em uma única fonte de infecção. Doença de tão longo periodo de incubação, como a em apreço, se fosse transmitida por contato interpessoal ou por outra fonte em que não ocorresse exposição simultânea, não daria a distribuição cronológica aqui desenhada.

\section{FIGURA 1}

Casos de hepatite segundo a semana de início da colúria ou TGP $\geqslant 100$ unidades e testagem do $\mathrm{Ag} \mathrm{HBs}$

(Instituição em S. Cristovão, Rio de Janeiro dezembro de 1973 a agosto de 1974)

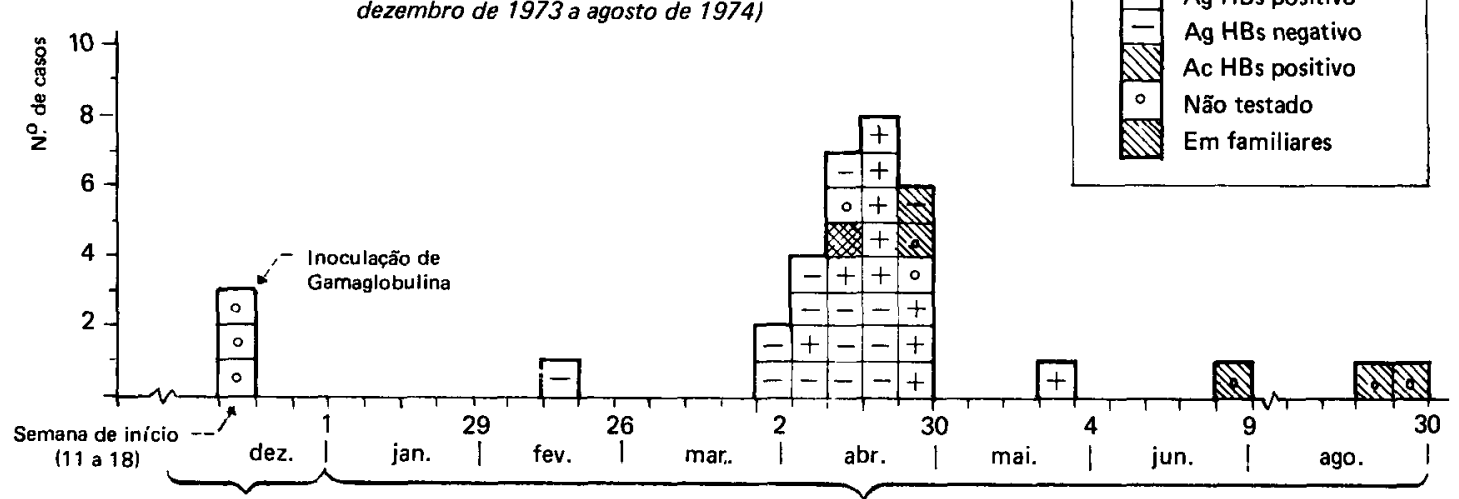

1973

1974

Em virtude de haver um intervalo de 14 semanas entre a grande aglomeração de casos, e ser este tempo o período de incubação da hepatite B, impõe-se formular a hipótese de que a primeira aglomeração de casos, - ou algum fator de risco a ela associado - foi a fonte de infecção da segunda aglomeração. De fato, a investigação epidemiológica revelou um acontecimento que se tornou muito importante: nos dias $17 \mathrm{e}$ 18.12.1973 foram aplicadas injeções de gamaglobulina em cerca de 120 empregados da empresa. Dos 27 casos centrados no mês de abril, 26 foram provenientes desses 120 empregados.

Os últimos quatro casos, iniciados em maio, junho e agosto e um caso do bloco de 27, ocorreram entre cerca de 20 familiares de empregados, que também tomaram injeção de gamaglobulina. Embora as injeções nesses 20 familiares não tenham sido aplicadas simultaneamente, nos cinco casos ocorreu notável regulari- dade do intervalo entre a injecão e o início da doença: três a quatro meses.

E como os quatro primeiros casos do surto epidêmico adquiriram a doença ? O caso iniciado em fevereiro fazia parte do grupo de empregados inoculados com gamaglobulina no dia 17.12.1973. Foi, provavelmente, o caso de menor período de incubação; ou então foi hepatite de inoculação por outro agente que não o vírus da hepatite $B$. Um dos três casos com início em dezembro, entrevistado pessoalmente, revelou que havia tomado uma injeção de gamaglobulina cerca de 100 dias antes de iniciar a doença, com a finalidade de "atenuar" uma agudização, tipo gripal, de sua bronquite crônica. Os outros dois, ocorridos em dezembro, foram investigados indiretamente, porque não foi possível entrevistá-los pessoalmente. A diretoria da firma confirmou que ambos os casos foram ictéricos, com o diagnóstico confirmado por 
médico. Ficaram afastados do trabalho por cerca de dois meses e se recuperaram integralmente. Um outro funcionário assegurou-nos que um desses casos também teria tomado uma injeção de gamaglobulina, para atenuar uma faringo-amigdalite. Um dos casos, alto funcionário da firma, não foi possivel ser investigado.

Paradoxalmente, o objetivo de injetar gamaglobulina nos funcionários foi "protegê-los" contra hepatite. Nos anos anteriores não havia ocorrido hepatite entre os empregados e, assim, a emergência dos três casos de dezembro deixouos atemorizados de, também, adquirirem a doença. A própria firma patrocinou a medida de aplicar a gamaglobulina, o que foi feito com seringas descartáveis, de plástico, desenvelopadas no ato e usada uma única vez. Já os 20 familiares de funcionários não sofreram inoculação simultânea porque esta foi uma decisão pessoal, em que um outro empregado com hepatite desejou proteger a sua família de adquirir a doença. Mas a gamaglobulina utilizada, fornecida pela empresa, foi da mesma que se usou nos empregados. As injeções nos familiares, em geral, foram aplicadas com seringas de vidro e em tempos diferentes, na vigência da grande concentração de casos, em abril, entre os empregados.

Achamos muito significativa a não ocorrência de hepatite em, pelo menos, 70 empregados e no grande número de familiares que não tomaram injeção de gamaglobulina.

\section{PRESENÇA DO ANTÍGENO DA HEPA- TITE B (Ag HB)}

Entre os 35 casos do surto epidêmico, 26 (74,3\%), foram testados para o $\mathrm{Ag} \mathrm{HB}$, cujos resultados estão expressos na Tabela 1. Observa-se que, no global, o $\mathrm{Ag} \mathrm{HB}$ esteve presente em $12(46,2 \%)$ pacientes. A distribuição destes casos segundo o tempo de doença evidencia que na hepatite B, como nas viroses em geral, o agente etiológico está presente no período agudo e, assim, o seu encontro torna-se menos provável à medida que se prolonga o tempo de doença. Foi notável que todos os oito pacientes testados com tempo de doença inferior a duas semanas foram positivos. A contradição da positividade observada na classe de duas a quatro, em relação a de quatro semanas e mais, pode ser devida a: um ou até os dois pacientes com maior tempo de doença seriam candidatos a "portadores" do Ag HB; problemas de memória dos pacientes cuja doença se prolongou por mais de duas semanas podem ter condicionado imprecisão ao se fixarem as datas e, por último, questões de acaso e tamanho dos grupos de observação. Mesmo com a contradição, a diferença na positi vidade foi significativa $\left(X^{2}=13,672\right)$, demonstrando que a garantia para se encontrar o $\mathrm{Ag} \mathrm{HB}$ está em pesquisá-lo duas primeiras semanas de doença.

Os resultados da testagem para o $\mathrm{Ag} \mathrm{HB}$ não deixaram dúvidas: trata-se de um surto epidêmico de hepatite B. A homogeneidade da clínica e da epidemiologia nos permite postular que todos os casos seriam positivos para o $\mathrm{Ag} \mathrm{HB}$ se tivessem sido testados para este antígeno nas duas primeiras semanas da doença.

\section{AS PROVÁVEIS FONTES DA INFECÇÃO}

A investigação epidemiológica evidenciou quatro acontecimentos comuns aos empregados nos seis meses que antecederam à grande concen-

Tabela 1

Pacientes testados para antígeno da hepatite $B(A g H B)$ segundo o tempo entre o início da doença e a coleta do sangue. Rio de Janeiro, 1974.

\begin{tabular}{|c|c|c|c|}
\hline \multirow{3}{*}{$\begin{array}{l}\text { TEMPO DE } \\
\text { DOENÇA EM } \\
\text { DIAS }\end{array}$} & \multicolumn{3}{|c|}{ PACIENTES TESTADOS* } \\
\hline & \multirow{2}{*}{$\frac{\text { Total }}{\text { No }}$} & \multicolumn{2}{|c|}{ Positivos } \\
\hline & & No & $\%$ \\
\hline$<\quad 14$ & 8 & 8 & 100,0 \\
\hline $14 \vdash 28$ & 11 & 2 & 18,2 \\
\hline$\geqslant 28$ & 7 & 2 & 28,5 \\
\hline TOTAL & 26 & 12 & 46,2 \\
\hline
\end{tabular}

(*) Pela contraimuno-eletroforese. 
tração de casos ocorrida no mês de abril, um dos quais provavelmente seria a fonte de infecção. O episódio da inoculação de gamaglobulina, contudo, já se tornara a esse tempo a hipótese mais plausivel. Tal fato, indubitavelmente, gerou tendenciosidades nesta testagem das hipóteses. Assim é que para a hipótese de injeção de gamaglobulina, cada um dos 32 pacientes, e o respectivo controle, foi investigado se havia ou não sido exposto a esse risco. Já para as demais hipóteses, além do número de pacientes ter sido menor, não se conseguiram controles suficientes para os casos.

Em que pesem as restrições desse estudo de caso-controle, os seus resultados contribuiram para identificar a fonte da infecção. A diferença de exposição entre o grupo de casos e o grupo controle foi significativa somente para injeção de gamaglobulina $(z=5,5907)$. Outras evidencias, juntamente com estas do estudo caso-controle, não deixaram dúvidas quanto à associação do surto epidêmico com a inoculação de gamaglobulina. A média do período de incubação foi de 116 dias, contados'entre a inoculação e o início da colúria.

\section{EXAMES LABORATORIAIS DA GAMAGLO- BULINA E DA ÁGUA}

Empregando-se três técnicas diferentes do teste de radioimuno-ensaio, encontrou-se o Ag HBs sob a forma de complexo imune em seis $(54,5 \%)$ das onze partidas de gamaglobulina examinadas (18). Tais resultados foram confirmados por outro laboratório de referência da Organização Mundial de Saúde 19 -

O exame bacteriológico da água, coletada em doze locais diferentes do edifício, não revelou presença de germes do grupo coli. Evidenciou-se, porém, na rede interna, uma concentração decrescente de cloro residual, o que pode ser atribuído ao envelhecimento da própria rede. *

Tabela II

Grupo de casos de hepatite e grupo controle distribuídos segundo as quatro mais prováveis fontes de infecção. Rio de Janeiro, 1974.

\begin{tabular}{|c|c|c|c|c|c|c|c|c|c|c|c|c|}
\hline \multirow{3}{*}{$\begin{array}{l}\text { GRUPOS } \\
\text { ESTUDADOS }\end{array}$} & \multicolumn{3}{|c|}{$\begin{array}{c}\text { INJEÇĀO DE } \\
\text { GAMAGLOBULINA (*) }\end{array}$} & \multicolumn{3}{|c|}{$\begin{array}{l}\text { REFEIÇÄO NA } \\
\text { FIRMA (**) }\end{array}$} & \multicolumn{3}{|c|}{$\begin{array}{l}\text { ÁGUA NA } \\
\text { FIRMA }(* *)\end{array}$} & \multicolumn{3}{|c|}{$\begin{array}{c}\text { PIC-NIC A } \\
\text { M. PEREIRA. }(* *)\end{array}$} \\
\hline & \multicolumn{2}{|c|}{ Sim } & \multirow[t]{2}{*}{ Total } & \multicolumn{2}{|c|}{$\operatorname{sim}$} & \multirow{2}{*}{$\frac{\text { Total }}{N^{\circ}}$} & \multicolumn{2}{|c|}{$\operatorname{sim}$} & \multirow{2}{*}{$\begin{array}{c}\text { Total } \\
\text { No }\end{array}$} & \multicolumn{2}{|c|}{ Sim } & \multirow[t]{2}{*}{ Total } \\
\hline & No & $\%$ & & $\mathrm{No}$ & $\%$ & & $N^{O}$ & $\%$ & & & $\%$ & \\
\hline CASO & 32 & 100,0 & 32 & 10 & 33,3 & 30 & 20 & 74,1 & 27 & 6 & 21,4 & 28 \\
\hline CONTROLE & 11 & 34,4 & 32 & 5 & 23,8 & 21 & 9 & 50,0 & 18 & 2 & 10,0 & 20 \\
\hline $\begin{array}{l}\text { AMBOS OS } \\
\text { GRUPOS }\end{array}$ & 43 & 67,2 & 64 & 15 & 29,4 & 51 & 29 & 64,4 & 45 & 8 & 16,7 & 48 \\
\hline
\end{tabular}

$(*) p<0,05 \quad$ (**) p >0,05

\section{CASOS DA POPULAÇÃO GERAL}

As características epidemiológicas mais importantes dos oito casos estão expressas no Quadro 1. Observa-se que todos são adultos jovens ou adultos, de classe social média e alta, e que em seis a gamaglobulina foi empregada com finalidade preventiva, por recomendação médica. Houve uma regularidade entre a injeção da gamaglobulina e o início da doença. Em quatro casos com datas precisas, o período de incubação médio foi de 106 dias. O intervalo entre o início da colúria e a queda da transaminase glutâmico-pirúvica a valores inferiores a 100 Unidades Frankel - na ausência de sinais e sintomas de hepatite - foi considerado como duração da doença. Nos cinco casos em que isso ficou conhecido, a duração média foi de $\mathbf{4 9}$ dias. Em seis pacientes testados para o $\mathrm{Ag} \mathrm{HB}$, apenas um não foi positivo, mas a sua testagem foi feita após 15 dias de doença, período em que a probabilidade de encontrar o Ag HB é baixa. Tal paciente evoluiu para uma forma crônica de hepatite, com grave comprometimento hepático. Os demais pacientes, embora

(* I Exames efetuados pelo Dept? de Saneamento da Escola Nacional de Saúde Pública - FIOCRUZ, coordenado pelo Prof. S. E. Cynamon. 
com icterícia e elevados valores de transaminase glutâmico-pirúvica, tiveram um quadro clínico que se enquadra no que se convencionou chamar de "hepatite aguda benigna".

A dimensão do presente problema na população foi muito mais extensa, pois os oito casos aqui relatados ocorreram entre pessoas que tomaram conhecimento preciso do risco a que se expuseram. Cinco delas têm intima relação com a prófissão médica (M.E.Q. é esposa de médico). Os outros três eram pacientes vinculados ao serviço médico onde emergiu a hipótese da transmissão pela gamaglobulina. Embora tenham aparecido, nesse periodo, notícias na impresa leiga de várias capitais brasileiras, associando a hepatite com injeção de gamaglobulina, é provável que a maioria de tais casos tenha sido imputada a outras causas.

\section{Quadro I}

Características epidemiológicas dos oito casos de hepatite provenientes da população geral. Rio de Janeiro - 1974

\begin{tabular}{|c|c|c|c|c|c|c|c|c|c|}
\hline $\begin{array}{l}\text { ORDEM } \\
\text { DE } \\
\text { INICIO }\end{array}$ & NOME & $\begin{array}{l}\text { IDADE } \\
\text { EM } \\
\text { ANOS }\end{array}$ & PROFISSĀO & $\begin{array}{c}\text { MOTIVO } \\
\text { DA } \\
\text { INOCULACÃO }\end{array}$ & $\begin{array}{c}\text { DATA } \\
\text { DA } \\
\text { INJEÇÃO }\end{array}$ & $\begin{array}{c}\text { INICIO } \\
\text { DA } \\
\text { COLÚRIA }\end{array}$ & 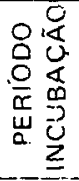 & 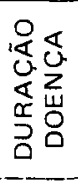 & $\begin{array}{c}\text { TESTAGEM } \\
\text { PARA O } \\
\text { Ag HBs }\end{array}$ \\
\hline 1 & M.E.O. & 50 & $\begin{array}{l}\text { Estudante de } \\
\text { psicologia }\end{array}$ & $\begin{array}{l}\text { Virose inespe- } \\
\text { cifica }\end{array}$ & 10.1973 & 31.01 .74 & - & - & Negativo \\
\hline 2 & L.D. & 21 & $\begin{array}{l}\text { Vestibulando de } \\
\text { medicina }\end{array}$ & Gripe & 15.01 .74 & 15.03 .74 & 60 & 53 & Positivo \\
\hline 3 & A.P.L. & 33 & Comerciante & Faringite & 20.01 .74 & 28.04 .74 & 108 & 51 & Positivo \\
\hline 4 & H.F. & 48 & Médico & $\begin{array}{l}\text { Contato de me- } \\
\text { ningite }\end{array}$ & 30.01 .74 & 29.04 .74 & 90 & 53 & Não testado \\
\hline 5 & J.F. & 23 & $\begin{array}{l}\text { Estudante de } \\
\text { medicina }\end{array}$ & - & 02.1974 & 16.05 .74 & - & - & Não testado \\
\hline 6 & P.E.H. & 28 & $\begin{array}{l}\text { Estudante de } \\
\text { medicina }\end{array}$ & - & 03.1974 & 04.05 .74 & - & 35 & Positivo \\
\hline 7 & A.R.C. & 27 & Bancário & Herpes labialis & 10.04 .74 & 27.09 .74 & 167 & 51 & Positivo \\
\hline 8 & L.M.C.B. & 3. 33 & Professora & Rubéola & 04.1974 & 11.07 .74 & - & - & Positivo \\
\hline
\end{tabular}

\section{DISCUSSÃO}

A questão central do presente trabalho são os elementos necessários para provar que a gamaglobulina tenha sido veículo do virus da hepatite. Os investigadores são unânimes em afirmar que esse produto terapêutico fica isento do referido vírus quando se obedece aos processos usuais para o seu preparo. Em abono desse conhecimento são suficientes as conclusões dos trabalhos de Schroeder e Mozen 15 , Zuckerman e cols. ${ }^{17}$, Beck e cols. ${ }^{1}$, Berg e cols. ${ }^{3}$ e Maycock ${ }^{10}$.

Epidemiologicamente, são raríssimas as observações que insinuaram alguma dúvida quanto à pureza da gamglobulina comercial. Cockburn ${ }^{4}$. ao investigar ininuciosamente um caso de hepatite, não relutou em afirmar que sua transmissão fora devida a uma injeção de gamaglobulina, aplicada cerca de três meses antes de se iniciar a doença. Responsabilizou o medicamento em si, e rião a seringa ou agulha. Não foi sem razão que naquela época uma revista médica altamente categorizada tenha afirmado que a gamaglobulina não estava inteiramente livre de transmitir o virus da hepatite ${ }^{5}$. Janeway ${ }^{9}$ relatou, também, um caso de hepatite que iniciou cerca de três meses após injeção de gamaglobulina, mas nâo se pronunciou quanto a essa provável associação.

No Brasil, Morgago e Fonte ${ }^{14}$ estudaram um surto epidêmico de hepatite, ocorrido cerca de seis meses após o aqui descrito, e que também foi transmitido por gamaglobúlina. Esse segundo surto epidêmico foi um acontecimento deplorá. vel, porque as injeções de gamaglobulina foram 
efetuadas num periodo em que o Ministério da Saúde já havia baixado dispositivo de lei sustando a fabricação da referida gamaglobulina, determinava sua apreensão nas farmácias e proibia sua comercialização em todo o território nacional. Bensabath ${ }^{2}$ informou ter conhecimento de surto epidêmico de hepatite, na cidade de Belém do Pará, ocorrido no mesmo período do que ora é relatado e que também fora transmitido por gamaglobulina.

Mendonça e cols. 11 responsabilizaram esse medicamento pela transmissão em, pelo menos, um dos pacientes por eles estudados. Silva e cols. 16 encontraram um excesso de prevalência do $\mathrm{Ag} H B$ entre pessoas que usaram gamaglobulina com finalidade profilática. Ademais, verificaram que entre 31 partidas de gamaglobulina, sete $(22,5 \%)$ eram positivas para o $\mathrm{Ag} \mathrm{HB}$.

As graves consequências, aqui relatadas, produzidas pela gamaglobulina e o encontro do $\mathrm{Ag} \mathrm{HB}$ em várias partidas desse medicamento, levam-no a concluir que houve uma grave fallha no seu preparo. A bula anexada à embalagem da gamaglobulina, vendida ao consumidor, informa, concisamente, que essa gamaglobulina é obtida de um "pool" de 10.000 doadores de sangue. Não consta, sequer, o processo utilizado no preparo.

\section{SUMMARY}

The authors studied an epidemic of hepatitis $B$ occurring in an institution located in the São Cristovão section of the city of Rio de Janeiro, Brasil. Of a total of 35 cases detected, 30 ocurred in employees of the institution and 5 in family members of the employees. All the cases were considered as benign acute hepatitis; all but two were iteric. Clinically, a marked articular involvement was noted, with intense arthralgia and pronounced restriction of movement, which regressed completely as soon as jaundice became evident. The chronological distribution was typical of simultaneous infection from a single source. Epidemiological investigation indicated that the source was commercially prepared pooled human gamma globulin. Ironically, injections were given, as prophylaxis against hepatitis with disposable syringes. During two days of application, approximately 120 employees received gamma globulin injections, among whom 27 developed hepatitis with a mean incubation period of 116 days. Twenty six patients were tested for $\mathrm{HBAg}$, with positive results in $12(46.2 \%) ; 8$ patients tested during the first two weeks of over disease were all positive. The epidemic outbreak occurred in conditions, though not premeditated, approximating to those of an experimental study.

In addition to the São Cristovão epidemic, the authors studied 8 cases seen at the hospital service where they worked. These cases presented characteristics distinguishing them from the the type of hepatitis case commonly treated in that hospital. All these 8 patients were of elevated socioeconomic conditions, and all had a history of having received injections of gamma globulin from the same commercial source as that which gave rise to the São Cristovão epidemic. In these cases the mean incubation period was 106 days, and 5 of 6 patients tested were positive for $\mathrm{HB} \mathrm{Ag}$.

Eleven lots of gamma globulin were tested in reference laboratories of the World Health Organization, six of these $(53,5 \%)$ were positive for $\mathrm{HB} \mathrm{Ag}$.

The authors conclude that there was a serious lapse in the process of preparation of the gamma globulin in question. It is recommended that the widespread assumption that this product is free of risks of transmitting hepatitis virus should be accepted with reservation.

\section{AGRADECIMENTOS}

Os autores agradecem a Dra. Maria Brasília Leme Lopes, presidente da então Comissão de Hemoterapia do Ministério da Saúde, pelo seu admirável empenho em esclarecer o problema, inclusive a solicitação de exames de laboratório da Gamaglobulina em diferentes laboratórios nacionais e estrangeiros.

Ao Prof. Szachna Eliasz Cynamon, Chefe do Departamento de Saneamento e Saúde Ambien. tal da Escola Nacional de Saúde Pública FIOCRUZ, pela realização dos exames laboratoriais de água e seu parecer sobre as condições de salubridade da instituição onde ocorreu o surto epidêmico.

\section{REFERÊNCIAS BIBLIOGRÁFICAS}

1. BECK, H., SCHMITT, H. and STüRNER, K.H. Au/SH Antigen in Human Plasma Fractions. Vox. Sang., $20(3): 281-282$, 1971.

2. BENSABATH, G. Informação pessoal ao XI Congresso da Soc. Bras.Med. Trop., Rio de Janeiro, 1975. 
3. BERG, R., BJÖRLING, H., BERNSTSEN, K., and ESPMARK, A. Recovery of Australia antigen from human plasma products separated by a modified COHN fractionation. Vox Sang., $22:(1): 1-13$, 1972.

4. COCKBURN, W.C., HARRINGTON, J.A., ZEITLIN, R.A., MORRIS, D., and CAMPS, F.E. Homologous serum Hepatitis and measeles prophylaxis. Brit. Med., 2 (4722) : 6-12, 1951.

5. Editorial. Gama globulin and Inoculation Hepatitis. Brit. Med.J., 2 (4722) : 36-37. 1951.

6. FOX, J.P., MANSO, C., PENNA, H.A., and PARÁ, M. Observations on the Occurrence of Icterus in Brazil Following Vaccination Against Yellow Fever. Am.J.Hyg., 36 (1) : 68-116, 1942.

7. GRAVES, R.J. A system of clinical medicine, p. 564. Dublin 1843. In SHERLOCK, $S$. The Course of Long Inoculation (virus B) Hepatitis. Brit. Med. Bull., $28(2): 109-113,1972$.

8. HAWLEY, W.L., MCFARLAN, A.M., STEIGMAN, A.J., MCMICHAEL, J., and DIBLE, J.H. Hepatitis Following Injection of Mumps Convalescent Plasma. Lancet, 1 (6304) : 818-821, 1944.

9. JANEWAY, C.A. Use $\neq 0$ concentrated human serum - Globulin in the prevention and attenuation of measles. Bull. $N$. Y, Acad.Med., 21 (4) : 202-222, 1945.

10. MAYCOCK, W. d'A. Hepatitis in Transfusion Services. Brit. Med. Bull., 28 (2) : 163-168, 1972.

11. MENDONÇA, J.S., MOSTÉRIO, L., NASSER, L.F.C. A AMATO NETO, V. Manifestações articulares da hepatite por vírus $\mathrm{B}$ : análise de 145 casos. XI Congr. Soc. Bras. Med. Trop., Rio de Janeiro, 1975. Resumo 186.

12. MIRICK, G.S., and SHANK, R.E. An Epidemic of Serum Hepatitis Studied Under Controlled Contitions. Trans. Am. Clin. Climat Assoc., 71:076-1959.

13. MORGADO, A.F. Hepatite transmitida por Gamaglobulina. Tese. Faculdade de Medicina da U.F.R.J., Rio de Janeiro. 1975. 73 pgs.

14. MORGADO, A.F. e FONTE, J.G. An outbreak of Hepatitis Attributable to inoculation with contaminated gamaglubulin. Bull. Pan. Am. Health Org., 13 (2) : 177-186, 1979.

15. SCHROEDER, D.D., MOZEN, M.M.

Australia Antigen: Distribution During COHN Ethanol Fractionation of Human Plasma. Science, 168: 1462-1463, 1970.

16. SILVA, L.C., SETTE Jr., H., ANTONÁCIO, F. e LOPES, J.D. Commercial Gammaglobulin (CGG) as a possible vehicle of trans. mission of $\mathrm{H} \mathrm{B}_{\mathrm{s}} \mathrm{Ag}$ in Familial Custering. Rev. Inst. Med. Trop. S.P., 19 (5) : 352-354, 1977.

17. ZUCKERMAN, A.J., TAYLOR, P.E., BIRD, D.G., and RUSSEL, S.M. The Australia (Hepatitis Associates) Antigen in Fibrinogen and other Fractions of Human Plasma. J. Clin. Pathol., 24 (1) : 2-7. 1971.

18. World Health Organization. Analysis Report Concerning Globulin Samples from Brazil. Geneve, 1974 (Confidential).

19. Word Health Organization reference Laboratory. London School of Hygiene and Tropical Medicine. Immunoglobulin Samples from Brazil, 1975. 